\title{
High-performance Hydrochromic Cotton Fabric Fabricated With CoCl2/waterborne Polyurethane for Air Humidity Detection
}

Jinju Zhang

Jiangnan University

Fangqing Ge

Jiangnan University

Jialing Tan

Jiangnan University

Yunjie Yin

Jiangnan University

Chaoxia Wang ( $\nabla$ wangchaoxia@sohu.com )

Jiangnan University https://orcid.org/0000-0001-6322-7606

\section{Research Article}

Keywords: waterborne polyurethane, $\mathrm{CoCl} 2$, hydrochromic, cotton fabric, humidity detection

Posted Date: September 21st, 2021

DOl: https://doi.org/10.21203/rs.3.rs-889278/v1

License: (9) This work is licensed under a Creative Commons Attribution 4.0 International License.

Read Full License 


\section{Abstract}

Hydrochromic materials has been a novel topic in the research of stimuli-responsive sensors and anticounterfeiting encryption. A high-performance hydrochromic cotton fabric is fabricated with $\mathrm{CoCl}_{2}$ /waterborne polyurethane via hot-press method. Moisture sensing metal salt cobalt chloride is introduced into waterborne polyurethane via physical doping to induce hydrochromic phenomenon. The hydrochromic cotton fabric possess superior fastness due to the hydrogen bonds formed by hydroxyl group on cotton fabric and carbonyl group, urethane bond, ether bond in waterborne polyurethane. Meanwhile, the hydroxyl group on cotton fabric and waterborne polyurethane endow hydrochromic cotton fabric with excellent hydrophilicity and high humidity sensitivity. Air humidity could be easily detected by hydrochromic cotton fabric. The absorption of humidity in rainy days led to pink color, resulting in a blue shift at $512 \mathrm{~nm}$. In contrast, hydrochromic cotton fabric turn to blue color below RH $59 \%$ in sunny days, leading to a red shift for up to $674 \mathrm{~nm}$. Moreover, the hydrochromic cotton fabric exhibited eminent stability and cyclicity in response to either dry state or wet condition. Based on these excellent properties, hydrochromic cotton fabric fabricated with $\mathrm{CoCl}_{2}$ / waterborne polyurethane are promising as smart sensors with potential application in sensitive $\mathrm{RH}$ detector, anti-counterfeiting technology and decorative coatings.

\section{Introduction}

Stimuli-responsive chromic materials(Yang et al. 2018; Jia et al. 2021; Liu et al. 2021; Samanta et al. 2021) such as photochromic,(Qi et al. 2021; Yang et al. 2021) hydrochromic,(Si et al. 2021; Sun et al. 2021) thermochromic,(Zhang et al. 2020; Kim et al. 2021) and electrochromic(Kim et al. 2010; Nguyen et al. 2021) that exhibit a colorimetric response to external stimuli are extensively investigated due to their novelty in popular culture and potential applications.(Eoh et al. 2021; Ma et al. 2021; Si et al. 2021) Of the stimuli-responsive chromic materials, the hydrochromic materials,(Mishra and Singh 2021) which undergo colorimetric transitions upon interaction with humidity or water, have been widely used for monitoring atmospheric humidity(Park et al. 2016a; Bilgin and Backhaus 2020) and shows important applications in sensors,(Sheng et al. 2014; Park et al. 2016a, b; Bilgin and Backhaus 2020) environmental monitoring,(Zhou et al. 2021) displays(Sheng et al. 2014; Ju et al. 2020) and anticounterfeiting encryption(Ju et al. 2020; Yu et al. 2020).

Hydrochromic materials which can change their color once a stimulus is applied can both detect a change in conditions and convey it to a user.(You et al. 2017; Hong et al. 2018) Compared with thermochromic, electrochromic, and photochromic strategies, hydrochromic materials are easy to authenticate by the naked eye without external instruments. Hydrochromic materials have a broad spectrum of applications,(Park et al. 2016b; Ni et al. 2019) such as breath detection, air humidity detection,(Zhou et al. 2021) anticounterfeiting encryption inks,(Kou et al. 2018) water content sensors, (Karimipour et al. 2020; Sun et al. 2021) rewritable papers(Mao et al. 2021), and human sweat pore mapping technologies.(Kitamura et al. 2018) Hydrochromic materials include graphene oxide,(Chi et al. 2021) triarylmethane proton transfer,(Jiang et al. 2021) metal salt with crystal water, photonic crystals 
(PCs),(Jung et al. 2021) polydiacetylenes (PDAs), cholesteric liquid crystals,(Stumpel et al. 2015; Meng et al. 2020; Momtaz and Chen 2020; Yoo et al. 2020) lanthanide-ion-coordinated supramolecular hydrogel(Yao et al. 2020), aggregation-induced-emission (AIE) molecular,(Jiang et al. 2021) and covalent organic framework(Kitamura et al. 2018).

Recently, many researchers have made considerable efforts to design and exploit new methods to develop hydrochromic materials and extend their applications. For example, Yang's(Lan et al. 2021) group prepared a bilayer film consisting of composed of liquid crystalline networks (LCN) film and hydrochromic aggregation-induced emission molecule-doped hydrophilic layer. The composite film can deform and change color when exposed to different humidity. Zhou's(Shi et al. 2021) group prepared a semi-interpenetrating network composed of a cholesteric main-chain polymer and a hygroscopic poly(ampholyte) to obtain obtained a dual responsive elastic cholesteric polymer material. When swelled with water, the material showed a redshift of the reflected color. Gao's(Bu et al. 2021) group synthesized vinylene-linked covalent organic frameworks VCOF-PyrBpy, showing fluorescent response to water due to hydrogen bonding and protonation. Wang's(Mao et al. 2021) group demonstrated an efficient and convenient strategy to fabricate rewritable paper based on reversible hydrochromism of donor-acceptor Stenhouse adducts (DASAs).

However, the complexity of the preparation process and discoloration mechanism limit its practical applications. Typical colorimetric $\mathrm{RH}$ indicator such as $\mathrm{CoCl}_{2}$-based humidity sensor have been presented due to its advantages of high sensitivity and reliability. (Xu et al. 2021) Long's group(You et al. 2017) fabricated humidity indicators based on composite polyamide $66 /$ cobalt chloride $\left(\mathrm{PA} 66 / \mathrm{CoCl}_{2}\right)$ nanofibrous membranes by electrospinning, which showed obviously color change from blue to pink as relative humidity $(\mathrm{RH})$ increasing from 12.4 to $97.2 \%$. Mariana-Dana Damaceanu(Damaceanu et al. 2016) prepared $\mathrm{CoCl}_{2}$ /polyimide hybrid materials, which showed a visible color change when exposed to moisture and reverted immediately to the original color by heating to reduce the humidity.

Moisture sensing metal salt cobalt chloride could be introduced into waterborne polyurethane via physical doping to induce hydrochromic phenomenon. Waterborne polyurethane is suitable for hydrochromic materials in the textile field because of its safe non-toxic properties and green environmentally friendly performances.(Wen et al. 2019; Zhang et al. 2019) Moreover, the hydrophilicity of waterborne polyurethane promotes the moisture absorption process of hydrochromic materials.(Dai et al. 2021)

In this work, we have successfully synthesized $\mathrm{CoCl}_{2} \cdot 6 \mathrm{H}_{2} \mathrm{O}$ /waterborne polyurethane hybrid films and connected with cotton fabric under the force of chemical cross-linking by hot-press method. The test methods of FTIR proved the successful preparation of $\mathrm{CoCl}_{2} \cdot 6 \mathrm{H}_{2} \mathrm{O}$ /waterborne polyurethane hybrid films. The discoloration mechanism of $\mathrm{CoCl}_{2} \cdot 6 \mathrm{H}_{2} \mathrm{O}$ was explored by UV-vis test. The molecular weight, thermal performance and wetting performance of $\mathrm{CoCl}_{2} \cdot 6 \mathrm{H}_{2} \mathrm{O}$ /waterborne polyurethane hybrid films were investigated. The discoloration performance and discoloration fatigue resistance of hydrochromic cotton fabrics were systematically characterized. The results showed that hydrochromic cotton fabric exhibiting 
high humidity sensitivity with obviously color change, superior fastness, outstanding reversibility and admirable thermal stability, implying this hydrochromic material a potential candidate in application of stimuli-responsive sensors, efficient $\mathrm{RH}$ detector, anti-counterfeiting technology and decorative coatings.

\section{Experimental Section}

\subsection{Materials}

Isophorone diisocyanate (IPDI) and Polycarbonate diol (PCDL2000) were acquired from Shanghai Aladdin Reagent Co., Ltd. Butyl tin dilaurate (DBTDL) and 2,2-Dihydroxymethyl butyric acid (DMBA) were obtained from Shanghai Macklin Biochemical Technology Co., Ltd. Butanediol (BDO) and triethylamine (TEA) were purchased from Sinopharm Chemical Reagent Co., Ltd. Tetrahydrofuran (THF), acetone, ethanol and N, N-Dimethylformamide (DMF) were supplied by Sinopharm Chemical Reagent Co., Ltd. Lithium chloride ( $\mathrm{LiCl})$, Sodium Bromide ( $\mathrm{NaBr})$, Sodium chloride $(\mathrm{NaCl})$, Potassium chloride $(\mathrm{KCl})$ and Potassium sulfate $\left(\mathrm{K}_{2} \mathrm{SO}_{4}\right)$ were

also obtained from Sinopharm Chemical Reagent Co., Ltd. Cotton fabric $\left(150 \mathrm{~g} / \mathrm{m}^{2}\right)$ was purchased from a local factory.

\subsection{Synthesis of $\mathrm{CoCl}_{2} \cdot 6 \mathrm{H}_{2} \mathrm{O} /$ waterborne polyurethane hybrid materials}

Dissolve 6.68g isophorone diisocyanate (IPDI) and $20 \mathrm{~g}$ polycarbonate diol 2000 (PCDL2000) in $10 \mathrm{ml}$ tetrahydrofuran (THF) into a three-necked flask, and add $0.2 \mathrm{~mL}$ butyl tin dilaurate (DBTDL). The reaction was conducted at $80{ }^{\circ} \mathrm{C}$ with $300 \mathrm{r} / \mathrm{min}$ mechanical stirring for $1.5 \mathrm{~h}$. Then, $0.74 \mathrm{~g}$ 2,2-Dimethylolbutyric acid (DMBA) was dissolved in $10 \mathrm{~mL}$ THF and added slowly to the pre-polymerized product. The oil bath reacted for $2 \mathrm{~h}$ with $400 \mathrm{r} / \mathrm{min}$ mechanical stirring. $0.90 \mathrm{~g}$ 1,4-butanediol (BDO) was added slowly to the system at $80^{\circ} \mathrm{C}$ for an additional $2 \mathrm{~h} .0 .51 \mathrm{~g}$ triethylamine (TEA) was added for neutralize the reaction at $40{ }^{\circ} \mathrm{C}$ for $0.5 \mathrm{~h}$. Finally, $3 \mathrm{~g} / 2 \mathrm{~g} / 1 \mathrm{~g} / 0 \mathrm{~g} \mathrm{CoCl}_{2} \cdot 6 \mathrm{H}_{2} \mathrm{O}$ was dissolved in $10 \mathrm{~mL}$ THF respectively, and added to the three-necked flask at a speed of $300 \mathrm{r} / \mathrm{min}$ under mechanical stirring for $20 \mathrm{~min}$. The prepared $\mathrm{CoCl}_{2} \cdot 6 \mathrm{H}_{2} \mathrm{O} /$ waterborne polyurethane hybrid materials were dried in a polytetrafluoroethylene mold. The schematic diagram of the synthesis of $\mathrm{CoCl}_{2} \cdot 6 \mathrm{H}_{2} \mathrm{O}$ /waterborne polyurethane hybrid materials is shown in Scheme 1.

\subsection{Preparation of $\mathrm{CoCl}_{2} \cdot 6 \mathrm{H}_{2} \mathrm{O} /$ waterborne polyurethane (CoPU) films}

The dried $\mathrm{CoCl}_{2} \cdot 6 \mathrm{H}_{2} \mathrm{O} /$ waterborne polyurethane hybrid materials were weighed $15 \mathrm{~g}$ respectively and dissolved in $73 \mathrm{ml}$ of dichloromethane solvent, and dried at room temperature to obtain a uniform $\mathrm{CoCl}_{2} \cdot 6 \mathrm{H}_{2} \mathrm{O} /$ waterborne polyurethane (CoPU) films. The waterborne polyurethane doped with $0 \mathrm{~g}$ $\mathrm{CoCl}_{2} \cdot 6 \mathrm{H}_{2} \mathrm{O}$ was named as $\mathrm{PU}$. The waterborne polyurethane doped with $1 \mathrm{~g} \mathrm{CoCl} \cdot 6 \mathrm{H}_{2} \mathrm{O}$ was named as $\mathrm{Co}_{1} \mathrm{PU}$. The waterborne polyurethane doped with $2 \mathrm{~g} \mathrm{CoCl}_{2} \cdot 6 \mathrm{H}_{2} \mathrm{O}$ was named as $\mathrm{Co}_{2} \mathrm{PU}$. The waterborne 
polyurethane doped with $3 \mathrm{~g} \mathrm{CoCl} 2 \cdot 6 \mathrm{H}_{2} \mathrm{O}$ was named as $\mathrm{Co}_{3} \mathrm{PU}$. The molar ratio of each component is illustrated in Table 1.

Table1. The proportion of components of $\mathrm{CoCl}_{2} \cdot 6 \mathrm{H}_{2} \mathrm{O} /$ waterborne polyurethane (CoPU) films.

\begin{tabular}{lllllll} 
Samples & \multicolumn{2}{l}{ Weight/g } & & & \\
\cline { 2 - 6 } & IPDI & PCDL2000 & DMBA & BDO & CoCl $_{2} \cdot 6 \mathrm{H}_{2} \mathrm{O}$ \\
\hline $\mathrm{PU}$ & 6.68 & 20.00 & 0.74 & 0.90 & 0 \\
\hline $\mathrm{Co}_{1} \mathrm{PU}$ & 6.68 & 20.00 & 0.74 & 0.90 & 1 \\
\hline $\mathrm{Co}_{2} \mathrm{PU}$ & 6.68 & 20.00 & 0.74 & 0.90 & 2 \\
\hline $\mathrm{Co}_{3} \mathrm{PU}$ & 6.68 & 20.00 & 0.74 & 0.90 & 3 \\
\hline
\end{tabular}

\subsection{Preparation of CoPU hydrochromic cotton fabric}

$15 \mathrm{~g}$ of $\mathrm{CoCl}_{2} \cdot 6 \mathrm{H}_{2} \mathrm{O} /$ waterborne polyurethane (CoPU) films were weighed for hot-press on $15^{\star} 15 \mathrm{~cm}$ cotton fabric. The hot-press process was conducted at $50{ }^{\circ} \mathrm{C}$ with $10 \mathrm{MPa}$ pressure for 10 min and $20 \mathrm{MPa}$ pressure for an additional $15 \mathrm{~min}$. Finally, CoPU hydrochromic cotton fabrics with $0.5 \mathrm{~mm}$ thick were obtained. The samples were named as PU hydrochromic cotton fabric, $\mathrm{Co}_{1} \mathrm{PU}$ hydrochromic cotton fabric, $\mathrm{Co}_{2} \mathrm{PU}$ hydrochromic cotton fabric, $\mathrm{Co}_{3} \mathrm{PU}$ hydrochromic cotton fabric $₫$ respectively.

\subsection{Characterization and Measurements}

UV-vis spectra of $\mathrm{CoCl}_{2} \cdot 6 \mathrm{H}_{2} \mathrm{O}$ in $\mathrm{H}_{2} \mathrm{O}$, acetone, ethanol and $\mathrm{N}$, N-Dimethylformamide (DMF) were acquired by using a UV-vis Spectrophotometer (Cary 50, Varian) under room temperature.

The Fourier transform infrared (FT-IR) spectra of $\mathrm{PU}, \mathrm{Co}_{1} \mathrm{PU}, \mathrm{Co}_{2} \mathrm{PU}, \mathrm{Co}_{3} \mathrm{PU}$ were monitored with a NICOLET is 10 transform infrared instrument (Thermo Fisher Scientific, Co. Ltd., China). Measurements were carried out within the wavenumber range of $500-4000 \mathrm{~cm}^{-1}$ under room temperature. The vitrification temperatures of $\mathrm{PU}, \mathrm{Co}_{1} \mathrm{PU}, \mathrm{Co}_{2} \mathrm{PU}$ and $\mathrm{Co}_{3} \mathrm{PU}$ were tested by differential thermal scanning calorimeter (Q200). Before the test, the polyurethane samples were placed in an oven at $80{ }^{\circ} \mathrm{C}$ for $24 \mathrm{~h}$ to remove the solvent, and about $5 \mathrm{mg}$ of the samples were weighed and put into a crucible for testing. The testing temperature range was $-80^{\circ} \mathrm{C}$ to $200{ }^{\circ} \mathrm{C}$. The heating rate was $10{ }^{\circ} \mathrm{C} / \mathrm{min}$, and the flow rate of nitrogen was $50 \mathrm{~mL} / \mathrm{min}$. A thermogravimetric analyzer (Q500) was used to study the thermal properties of $\mathrm{PU}, \mathrm{Co}_{1} \mathrm{PU}, \mathrm{Co}_{2} \mathrm{PU}$, and $\mathrm{Co}_{3} \mathrm{PU}$. 4-6 mg of dried polyurethane were weighed into a crucible for thermal performance analysis. The test temperature range was set to $25 \sim 500^{\circ} \mathrm{C}$, and the heating rate was 20 ${ }^{\circ} \mathrm{C} / \mathrm{min}$. The measurement was performed under a nitrogen atmosphere. Gel permeation chromatography (GPC, Waters THF, USA) was applied to analyze the molecular weight distributions of polyurethanes at 35 
${ }^{\circ} \mathrm{C}$ with THF as the mobile phase. Approximately $20 \mu \mathrm{L}$ of a polyurethane solution with a concentration of $10 \mathrm{mg} / \mathrm{mL}$ was injected.

The surface morphologies of $\mathrm{PU}, \mathrm{Co}_{1} \mathrm{PU}, \mathrm{Co}_{2} \mathrm{PU}, \mathrm{Co}_{3} \mathrm{PU}$ hydrochromic cotton fabric were observed by scanning electron microscopy (SEM, Carl Zeiss Microscopy, Germany) under room temperature. The chemical compositions of $\mathrm{CO}_{3} \mathrm{PU}$ hydrochromic cotton fabric was characterized by energy dispersive spectroscopy (EDS). The structures of $\mathrm{CoCl}_{2} \cdot 6 \mathrm{H}_{2} \mathrm{O}$ and $\mathrm{Co}_{1} \mathrm{PU}, \mathrm{Co}_{2} \mathrm{PU}, \mathrm{Co}_{3} \mathrm{PU}$ hydrochromic cotton fabric were characterized by $\mathrm{X}$-ray diffractometer from Japan over the $2 \theta$ range of $5-80^{\circ}$. The contact angle (CA) of $\mathrm{PU}, \mathrm{Co}_{1} \mathrm{PU}, \mathrm{Co}_{2} \mathrm{PU}, \mathrm{Co}_{3} \mathrm{PU}$ hydrochromic cotton fabric measurements were carried out by a Drop Shape Analyzer 100 (Krüss, German) using liquid droplets of $5 \mu \mathrm{L}$ in volume.

The color parameters $\left(a^{*}, b^{*}, L^{*}, K / S\right.$ value $)$ of $\mathrm{Co}_{1} \mathrm{PU}, \mathrm{Co}_{2} \mathrm{PU}, \mathrm{Co}_{3} \mathrm{PU}$ hydrochromic cotton fabric were tested by an Xrite-8400 spectrophotometer under a D65 illuminant using a $10^{\circ}$ standard observer. The $\mathrm{K} / \mathrm{S}$ value represents the apparent color depth. Water vapor capture was measured by setting dried $\mathrm{Co}_{1} \mathrm{PU}, \mathrm{Co}_{2} \mathrm{PU}, \mathrm{Co}_{3} \mathrm{PU}$ hydrochromic cotton fabric in a humidity container with controllable $\mathrm{RH}$ on the basis of the saturated salt solution composition. The various saturated salt solutions with different humidity gradients ( $\mathrm{RH} 11 \%, \mathrm{RH} 59 \%, \mathrm{RH} 75 \%, \mathrm{RH} 85 \%, \mathrm{RH} 98 \%$ ) were prepared with saturated anhydrous $\mathrm{LiBr}, \mathrm{LiCl}, \mathrm{CH}_{3} \mathrm{COOK}, \mathrm{NaBr}, \mathrm{KCl}$ solutions and distilled water. Heating to $60^{\circ} \mathrm{C}$ represent $\mathrm{RH} 0 \%$, breathing or using a humidifier to reach $\mathrm{RH} 100 \%$. These glass containers were placed at $25^{\circ} \mathrm{C}$. After equilibration, $\mathrm{Co}_{1} \mathrm{PU}, \mathrm{Co}_{2} \mathrm{PU}, \mathrm{Co}_{3} \mathrm{PU}$ hydrochromic cotton fabrics were placed in the above different humidity gradients microenvironment. Then, the color parameters of $\mathrm{Co}_{1} \mathrm{PU}, \mathrm{Co}_{2} \mathrm{PU}, \mathrm{Co}_{3} \mathrm{PU}$ hydrochromic cotton fabrics were obtained by Xrite-8400 spectrophotometer under a D65 illuminant. The washing fastness and rubbing fastness of CoPU hydrochromic cotton fabrics were determined in accordance with AATCC 61-2006 and AATCC 8-2007 standards respectively. The color fastness of CoPU hydrochromic cotton fabrics were evaluated by gray sample card.

\section{Results And Discussion}

\subsection{Hydrochromic behavior of $\mathrm{CoCl}_{2} \cdot 6 \mathrm{H}_{2} \mathrm{O}$}

Hydrochromic performance of $\mathrm{CoCl}_{2} \cdot 6 \mathrm{H}_{2} \mathrm{O}$ in $\mathrm{H}_{2} \mathrm{O}$, acetone, ethanol and $\mathrm{N}$, $\mathrm{N}$-Dimethylformamide (DMF) were investigated, respectively. As shown in Fig. 1, the $\mathrm{CoCl}_{2} \cdot 6 \mathrm{H}_{2} \mathrm{O} / \mathrm{H}_{2} \mathrm{O}$ solution displayed pink color, and the corresponding absorption peak was at $512 \mathrm{~nm}$. $\mathrm{CoCl}_{2} \cdot 6 \mathrm{H}_{2} \mathrm{O}$ combines with water molecules to form $\left[\mathrm{Co} \cdot\left(\mathrm{H}_{2} \mathrm{O}\right)_{6}\right]^{2+}$, so that the salt solution $\left[\mathrm{Co} \cdot\left(\mathrm{H}_{2} \mathrm{O}\right)_{6}\right]^{2+} \cdot 2 \mathrm{Cl}^{-}$exhibits pink color. While $\mathrm{CoCl}_{2} \cdot 6 \mathrm{H}_{2} \mathrm{O}$ in acetone, ethanol and N, N-Dimethylformamide (DMF) solution displayed blue color. The blue color is the darkest in DMF with two absorption bands centered at $674 \mathrm{~nm}$ and $608 \mathrm{~nm}$, followed by acetone with two absorption bands centered at $674 \mathrm{~nm}$ and $580 \mathrm{~nm}$, and the lightest blue in ethanol with an absorption band centered at $658 \mathrm{~nm}$. The polarity of the three organic solvents is, $\mathrm{N}, \mathrm{N}$-Dimethylformamide (DMF), acetone and ethanol, so $\mathrm{CoCl}_{2} \cdot 6 \mathrm{H}_{2} \mathrm{O}$ in acetone, ethanol and $\mathrm{N}, \mathrm{N}$-Dimethylformamide (DMF) solution displayed different shades of blue color. When $\mathrm{CoCl}_{2} \cdot 6 \mathrm{H}_{2} \mathrm{O}$ was in an organic solvent, its two crystal 
waters were taken by the solvent with high polarity, and the $\mathrm{CoCl}_{2} \cdot 6 \mathrm{H}_{2} \mathrm{O}$ that loses two crystal waters changed from red to blue.

\subsection{Synthesis and structural characterization of CoPU films}

To demonstrate the successful synthesis of polyurethane, the chemical structures of $\mathrm{CoCl}_{2} \cdot 6 \mathrm{H}_{2} \mathrm{O}$ /waterborne polyurethane (CoPU) films were tested (Fig. 2). The disappearance of the absorption peak at $2270 \mathrm{~cm}^{-1}$ and the appearance of $\mathrm{N}-\mathrm{H}$ in the carbamate at $3387 \mathrm{~cm}^{-1}$ and $\mathrm{C}=0$ at 1739 $\mathrm{cm}^{-1}$ proved the successful synthesis of PU. The typical absorption peak at $1739 \mathrm{~cm}^{-1}$ was ascribed to $\mathrm{C}=0$ stretching vibration, and the peak at $1242 \mathrm{~cm}^{-1}$ was assigned to $\mathrm{C}-\mathrm{O}-\mathrm{C}$ stretching vibration, indicating that polycarbonate diol 2000 (PCDL2000) was successfully introduced into the polyurethane polymer chain. The successful access of PCDL2000 can improve the hydrophilicity of polyurethane, which is beneficial to the humidity-sensitive discoloration ability of $\mathrm{CoCl}_{2} \cdot 6 \mathrm{H}_{2} \mathrm{O}$ /waterborne polyurethane (CoPU) films.

\subsection{Molecular weight and thermal stability of CoPU films}

We summarized the number average weight $(\mathrm{Mn})$, the weight average molecular weight $(\mathrm{Mw})$, the molecular weight at the midpoint (retention time) of the normal distribution of molecular weight (Mp) and polydispersity indexes (PDI) of the prepared polyurethane in Fig.3. The results showed that the number average molecular weights $(\mathrm{Mn})$ of the prepared polyurethane was 12180 . Therefore, the prepared polyurethane has moderate hardness, which is suitable for hot pressing on cotton fabric. Appropriate hardness of the prepared polyurethane also plays a significant role in hydrochromic process. High molecular weight causes polyurethane to be too hard, retarding its hygroscopicity process. Low molecular weight causes polyurethane to be too soft, making the surface become sticky after hygroscopic process. The results were found that PDI of the prepared polyurethane was 1.71. The prepared polyurethane exhibited small PDI, which possessed good uniformity.

In order to investigate the thermal performance of $\mathrm{CoCl}_{2} \cdot 6 \mathrm{H}_{2} \mathrm{O}, \mathrm{PU}, \mathrm{Co}_{1} \mathrm{PU}, \mathrm{Co}_{2} \mathrm{PU}, \mathrm{Co}_{3} \mathrm{PU}$, the thermosgravimetric curves of TGA and DTG were demonstrated in Fig.4. Thermal degradation process of $\mathrm{CoCl}_{2} \cdot 6 \mathrm{H}_{2} \mathrm{O}, \mathrm{PU}, \mathrm{Co}_{1} \mathrm{PU}, \mathrm{Co}_{2} \mathrm{PU}, \mathrm{Co}_{3} \mathrm{PU}$ were recorded in Fig.4. In Fig.4(b), thermal degradation process of $\mathrm{CoCl}_{2} \cdot 6 \mathrm{H}_{2} \mathrm{O}$ can be split into two stages. Firstly, degradation of crystal waters occurred around $100{ }^{\circ} \mathrm{C}$. The weight of $\mathrm{CoCl}_{2} \cdot 6 \mathrm{H}_{2} \mathrm{O}$ lost $15.42 \%$, which indicating that $\mathrm{CoCl}_{2} \cdot 6 \mathrm{H}_{2} \mathrm{O}$ lost two crystal waters. In the second stage, the maximum degradation rates were corresponding to $780.8{ }^{\circ} \mathrm{C}$. The weight of $\mathrm{CoCl}_{2} \cdot 6 \mathrm{H}_{2} \mathrm{O}$ lost completely, which indicating that $\mathrm{CoCl}_{2} \cdot 6 \mathrm{H}_{2} \mathrm{O}$ lost six crystal waters and the entire system was almost completely degraded due to the high temperature at this stage. Therefore, the hydrochromic mechanism of cobalt chloride is the loss of two crystal waters at low temperature. In Fig.4(c), thermal degradation process of the prepared polyurethane can be divided into two stages. In the first stage, the degradation temperature was below $200{ }^{\circ} \mathrm{C}$, which was attributed to moisture and residual solvent. The second decomposition range was occurred at $300-400{ }^{\circ} \mathrm{C}$ due to the dissociation of urethane bonds to 
break the macromolecular chain. In Fig.4(d-f), thermal degradation process of $\mathrm{CoCl}_{2} \cdot 6 \mathrm{H}_{2} \mathrm{O}$ / waterborne polyurethane (CoPU) films can be divided into two stages. The degradation temperature in the first stage was below $200{ }^{\circ} \mathrm{C}$ attributed to moisture and residual solvent. The second stage above $300{ }^{\circ} \mathrm{C}$ is the degradation process of urethane bonds dissociation, which is the process of maximum weightlessness. The maximum weightlessness temperature was $335.47^{\circ} \mathrm{C}, 330.0^{\circ} \mathrm{C}$ and $330.8^{\circ} \mathrm{C}$, respectively. This proves that CoPU films have good thermal stability. High temperature accelerates water vapor evaporation, so high thermal degradation temperature of CoPU films will not affect the hydrochromic performance of CoPU films.

The thermal performance of $\mathrm{CoCl}_{2} \cdot 6 \mathrm{H}_{2} \mathrm{O} /$ waterborne polyurethane (CoPU) films with different $\mathrm{CoCl}_{2} \cdot 6 \mathrm{H}_{2} \mathrm{O}$ contents was obtained by DSC curves as plotted in Fig.5. It was found that the glass transition temperature $(\mathrm{Tg})$ of the prepared polyurethane was around $-17.6^{\circ} \mathrm{C}$, demonstrating that the prepared polyurethane exhibited high fluidity at room temperature. According to the DSC curves of CoPU films in Fig. 5 , it can be concluded that the glass transition temperatures of $\mathrm{Co}_{1} \mathrm{PU}, \mathrm{Co}_{2} \mathrm{PU}$ and $\mathrm{Co}_{3} \mathrm{PU}$ were $-24.5^{\circ} \mathrm{C},-37.6^{\circ} \mathrm{C}$ and $-17.8^{\circ} \mathrm{C}$, respectively. The low glass transition temperature $(\mathrm{Tg})$ of $\mathrm{CoCl}_{2} \cdot 6 \mathrm{H}_{2} \mathrm{O} /$ waterborne polyurethane (CoPU) films made it highly elastic at room temperature. The segments of CoPU films started to move at room temperature, accelerating moisture absorption process. As a result, low glass transition temperature $(\mathrm{Tg})$ improves the sensitivity of hydrochromic process.

\subsection{Characterizations of CoPU hydrochromic cotton fabric}

In order to further improve the moisture absorption sensitivity of $\mathrm{CoCl}_{2} \cdot 6 \mathrm{H}_{2} \mathrm{O} /$ waterborne polyurethane (CoPU) films, the CoPU films were combined with cotton fabric by hot pressing. The surface morphologies of cotton fabric and CoPU hydrochromic cotton fabrics were examined by SEM (Fig. 6). It is obvious that the surface of cotton fabrics were clearly distributed fibers, while the surface of CoPU hydrochromic cotton fabrics were coated with smooth films, proving $\mathrm{CoCl}_{2} \cdot 6 \mathrm{H}_{2} \mathrm{O}$ / waterborne polyurethane (CoPU) films has been combined onto the surface of cotton fabrics firmly. The hydroxyl group on the cotton fabric and the carbonyl group, urethane bond and ether bond in the CoPU films form hydrogen bonds, so that the CoPU hydrochromic cotton fabric has good fastness. Meanwhile, the hydroxyl group on the cotton fabric and the hydroxyl group in the CoPU films possessed CoPU hydrochromic cotton fabric good hydrophilicity, making it easier to capture water molecules in the environment. Moreover, the close contact between CoPU films and cotton fabric made CoPU hydrochromic cotton fabric capture water molecules in the air, so that CoPU hydrochromic cotton fabric showed rapid response to humidity change.

The chemical compositions of $\mathrm{Co}_{3} \mathrm{PU}$ hydrochromic cotton fabric surface were examined through the EDS analysis. As shown in Fig.7, elemental mappings of $\mathrm{Co}_{3} \mathrm{PU}$ hydrochromic cotton fabric showed that the distribution of $\mathrm{Co}$ and $\mathrm{Cl}$ were uniform across the whole $\mathrm{Co}_{3} \mathrm{PU}$ hydrochromic cotton fabric surface, demonstrating that $\mathrm{CoCl}_{2} \cdot 6 \mathrm{H}_{2} \mathrm{O}$ has been successfully introduced into the prepared waterborne polyurethane and $\mathrm{Co}_{3} \mathrm{PU}$ films were well combined onto the surface of cotton fabric. 
The crystalline structures of $\mathrm{CoCl}_{2} \cdot 6 \mathrm{H}_{2} \mathrm{O}$ and CoPU hydrochromic cotton fabric were identified by X-ray diffraction (XRD). The XRD patterns of $\mathrm{CoCl}_{2} \cdot 6 \mathrm{H}_{2} \mathrm{O}$ was described in Fig.8. $\mathrm{CoCl}_{2} \cdot 6 \mathrm{H}_{2} \mathrm{O}$ had corresponding crystalline structure at $2 \theta=16.55^{\circ}, 21.13^{\circ}, 33.54^{\circ}, 38.28^{\circ}$ and $44.12^{\circ}$ characteristic diffraction peaks. After hot-press process, the characteristic diffraction peaks of $\mathrm{CoCl}_{2} \cdot 6 \mathrm{H}_{2} \mathrm{O}$ crystalline structure were reflected on CoPU hydrochromic cotton fabric, which proved that CoPU films were combined with the surface of cotton fabric firmly.

Considering that CoPU hydrochromic cotton fabric will be subjected to wet conditions during hydrochromic process, the contact angle of CoPU hydrochromic cotton fabric should be tested. The contact angle of $\mathrm{Co}_{0} \mathrm{PU}$ hydrochromic cotton fabric, $\mathrm{Co}_{1} \mathrm{PU}$ hydrochromic cotton fabric, $\mathrm{Co}_{2} \mathrm{PU}$ hydrochromic cotton fabric and $\mathrm{Co}_{3} \mathrm{PU}$ hydrochromic cotton fabric were tested. The results were shown in Fig. 9. The water contact angle of $\mathrm{Co}_{0} \mathrm{PU}, \mathrm{Co}_{1} \mathrm{PU}, \mathrm{Co}_{2} \mathrm{PU}$ and $\mathrm{Co}_{3} \mathrm{PU}$ were $63.32^{\circ}, 64.10^{\circ}, 63.87^{\circ}$ and $66.62^{\circ}$, respectively. The data showed that CoPU hydrochromic cotton fabric had strong hydrophilicity. Furthermore, strong hydrophilicity provided a prerequisite for the hydrochromic performance of CoPU hydrochromic cotton fabric.

\subsection{Humidity-sensitive discoloration performance and mechanism of CoPU hydrochromic cotton fabric}

The amount of moisture in the environment is of vital importance in affecting the discoloration of CoPU hydrochromic cotton fabric. In order to analyze the hydrochromic performance of CoPU hydrochromic cotton fabric, color parameters were monitored by a computer color measurement and color matching instrument. The results are shown in Fig. 10. After being placed in increasing humidity container, the $a^{*}$ value of $\mathrm{Co}_{1} \mathrm{PU}$ hydrochromic cotton fabric changed from -11.99 to 12.39 , the $\mathrm{b}^{*}$ value of $\mathrm{Co}_{1} \mathrm{PU}$ hydrochromic cotton fabric changed from -17.19 to -2.54 , and the corresponding discoloration was changed from blue to pink. While the $\mathrm{a}^{*}$ value of $\mathrm{Co}_{2} \mathrm{PU}$ hydrochromic cotton fabric changed from -21.85 to 12.88 , the $b^{*}$ value of $\mathrm{Co}_{2} \mathrm{PU}$ hydrochromic cotton fabric changed from -23.72 to -1.95 , and the corresponding discoloration was changed from blue to pink. At the same time, the a* value of $\mathrm{Co}_{3} \mathrm{PU}$ hydrochromic cotton fabric changed from -6.61 to 14.05 , the $b^{*}$ value of $\mathrm{Co}_{3} \mathrm{PU}$ hydrochromic cotton fabric changed from -38.96 to 0.16 , and the corresponding discoloration was changed from blue to pink.

As shown in Fig10, CoPU hydrochromic cotton fabrics exhibited blue color below $\mathrm{RH} 59 \%$, and turned to pink color above $\mathrm{RH} 59 \%$. With the change of hue, the peaks of the corresponding $\mathrm{K} / \mathrm{S}$ value also changed. Notably, as the amount of $\mathrm{CoCl}_{2} \cdot 6 \mathrm{H}_{2} \mathrm{O}$ increased, the color below $\mathrm{RH} 59 \%$ became bluer and the color above RH59\% became pinker. The increase of $\mathrm{CoCl}_{2} \cdot 6 \mathrm{H}_{2} \mathrm{O}$ would increase the degree of $\mathrm{CoCl}_{2} \cdot 6 \mathrm{H}_{2} \mathrm{O}$ content in CoPU films, which can increase the depth of color to some degree. More interestingly, compared with other hydrochromic materials, the color change of CoPU hydrochromic cotton fabric was a process of color mutation at $\mathrm{RH} 59 \%$.

Due to their excellent hydrochromic performance, CoPU hydrochromic cotton fabrics were applied to fabricate barometer. In sunny days, there exists low humidity in the atmosphere, the moisture on the 
CoPU hydrochromic fabrics become less, and $\mathrm{CoCl}_{2} \cdot 6 \mathrm{H}_{2} \mathrm{O}$ in the CoPU films lose two crystal waters and show blue color. When it is rainy, environment humidity is high, the CoPU hydrochromic fabrics absorb moisture. CoPU films regain crystal water and turn to pink color. That is blue color in sunny days while pink color in rainy days. Moreover, the hydroxyl group on the cotton fabric and the prepared polyurethane possessed CoPU hydrochromic cotton fabrics good hydrophilicity and superior humidity sensitivity. Furthermore, the hydrogen bonds formed between hydroxyl group on cotton fabric and carbonyl group, urethane bond, ether bond in the CoPU films made CoPU hydrochromic cotton fabric obtained good fastness. Totally, the observations reveal that CoPU hydrochromic cotton fabric could be employed in monitoring weather changes through color change.

In order to characterize the humidity-sensitive discoloration reversibility of CoPU hydrochromic cotton fabric, a more concrete study on the color-change of CoPU hydrochromic cotton fabric was conducted by analyzing the variation of $a^{*}$ and $b^{*}$ values during drying and wetting. The results were showed in Fig12, it can be seen that in the 10 measured cycles, $a^{*}$ and $b^{*}$ values of CoPU hydrochromic cotton fabric had no obvious change. The K/S value of CoPU hydrochromic cotton fabric was at $670 \mathrm{~nm}$, and the color appeared blue. In 10 cycles, the $a^{*}$ value of $\mathrm{Co}_{1} \mathrm{PU}$ hydrochromic cotton fabric was about -20 in dry conditions and 8 in wet conditions, while $b^{*}$ value of $\mathrm{Co}_{1} \mathrm{PU}$ hydrochromic cotton fabric was about -15 in dry conditions and 5 in wet conditions. The $a^{*}$ value of $\mathrm{Co}_{2} \mathrm{PU}$ hydrochromic cotton fabric was about -25 in dry conditions and 8 in wet conditions, while $b^{*}$ value of $\mathrm{Co}_{2} \mathrm{PU}$ hydrochromic cotton fabric was about -20 in dry conditions and 5 in wet conditions. The $a^{*}$ value of $\mathrm{Co}_{3} \mathrm{PU}$ hydrochromic cotton fabric was about -25 in dry conditions and 10 in wet conditions, while $b$ * value of $\mathrm{Co}_{1} \mathrm{PU}$ hydrochromic cotton fabric was about -25 in dry conditions and 7 in wet conditions. It can be concluded that with the increasement of $\mathrm{CoCl}_{2} \cdot 6 \mathrm{H}_{2} \mathrm{O}$, the CoPU hydrochromic cotton fabric exhibited deeper bluer color in dry conditions while slightly pink color change in wet conditions. In 10 cycles, CoPU hydrochromic cotton fabric alternately reciprocated between blue and pink. In summary, CoPU hydrochromic cotton fabric owns the superior stability and repeatability.

The durability of CoPU hydrochromic cotton fabrics were tested (Table 2). The wet rubbing fastness and washing fastness were investigated, respectively. For wet rub fastness, the discoloring fastness and staining fastness of CoPU hydrochromic cotton fabrics have reached 3-4 grade and 4 grade. Meanwhile, for washing fastness, the discoloring fastness and staining fastness of CoPU hydrochromic cotton fabrics have reached 3 grade and $3-4$ grade. $\mathrm{CoCl}_{2} \cdot 6 \mathrm{H}_{2} \mathrm{O}$ was wrapped in the prepared polyurethane, making it difficult for water and external forces to remove $\mathrm{CoCl}_{2} \cdot 6 \mathrm{H}_{2} \mathrm{O}$ from the prepared polyurethane. Simultaneously, the good color fastness of CoPU hydrochromic cotton fabrics can be contributed to the formation of hydrogen bonds between hydroxyl group on cotton fabrics and the carbonyl group, urethane bond, ether bond in the CoPU films.

Table2 Color fastness of CoPU hydrochromic cotton fabrics. 


\begin{tabular}{|lllll|}
\hline \multirow{2}{*}{ Samples } & \multicolumn{2}{l}{ Wet rub fastness(grade) } & \multicolumn{2}{l|}{ Washing fastness(grade) } \\
\cline { 2 - 5 } & Discoloring & Staining & Discoloring & Staining \\
\hline $\mathrm{Co}_{1} \mathrm{PU}$ & $3-4$ & 4 & 3 & $3-4$ \\
\hline $\mathrm{Co}_{2} \mathrm{PU}$ & $3-4$ & 4 & $3-4$ & 3 \\
\hline $\mathrm{Co}_{3} \mathrm{PU}$ & $3-4$ & 4 & 3 & 3 \\
\hline
\end{tabular}

\section{Conclusion}

In this work, we have successfully developed hydrochromic cotton fabric based on $\mathrm{CoCl}_{2} /$ waterborne polyurethane by facial hot-pressing method. Hydrochromic performance was constructed by moisture sensing metal salt cobalt chloride doped into waterborne polyurethane. The hydrogen bonds formed between cotton fabric and waterborne polyurethane possessed hydrochromic cotton fabric superior fastness. Moreover, hydrochromic cotton fabric obtained excellent hydrophilicity and high humidity sensitivity due to the hydroxyl group on cotton fabric and waterborne polyurethane. Hydrochromic cotton fabric presented pink color with a blue shift for up to $512 \mathrm{~nm}$ above $\mathrm{RH} 59 \%$, while turned to blue color with a red shift for up to $674 \mathrm{~nm}$ below RH 59\%. More interestingly, upon exposure to sunny and rainy days, hydrochromic cotton fabric presented blue and pink color, respectively, realizing air humidity monitoring. In 10 wet-dry cycles, the color of hydrochromic cotton fabric had no obvious change, showing eminent reversibility. In summary, this kind of hydrochromic cotton fabric fabricated with $\mathrm{CoCl}_{2}$ /waterborne polyurethane possess high humidity sensitivity, superior fastness, outstanding reversibility and admirable thermal stability is promised to be used in a wide range of applications, such as stimuli-responsive sensors, efficient RH detector, anti-counterfeiting technology and decorative coatings.

\section{Declarations}

\section{Declaration of interests}

The authors declare no competing financial interest.

\section{Acknowledgment}

This study was financially supported by the National Natural Science Foundation of China (21975107), Natural Science Foundation of Jiangsu Province (SBK2019020945) and Fundamental Research Funds for the Central Universities (JUSRP51724B).

\section{References}


Bilgin M, Backhaus J (2020) Development of an irreversible hydrochromic ink for smart packaging. J Print Media Technol Res 9:137-143. https://doi.org/10.14622/JPMTR-2004

Bu R, Zhang L, Liu XY, et al (2021) Synthesis and Acid-Responsive Properties of a Highly Porous VinyleneLinked Covalent Organic Framework. ACS Appl Mater Interfaces 13:26431-26440.

https://doi.org/10.1021/acsami.1c01791

Chi H, Ze LJ, Zhou X, Wang F (2021) GO film on flexible substrate: An approach to wearable colorimetric humidity sensor. Dye Pigment 185:108916. https://doi.org/10.1016/j.dyepig.2020.108916

Dai M, Zhai Y, Zhang Y (2021) A green approach to preparing hydrophobic, electrically conductive textiles based on waterborne polyurethane for electromagnetic interference shielding with low reflectivity. Chem Eng J 421:127749. https://doi.org/10.1016/j.cej.2020.127749

Damaceanu MD, Sava I, Constantin CP (2016) The chromic and electrochemical response of CoCl2 Filled polyimide materials for sensing applications Dedicated to the 150th anniversary of the Romanian Academy. Sensors Actuators, B Chem 234:549-561. https://doi.org/10.1016/j.snb.2016.04.172

Eoh H, Jung Y, Park C, et al (2021) Photonic Crystal Palette of Binary Block Copolymer Blends for Full Visible Structural Color Encryption. Adv Funct Mater 2103697:2103697. https://doi.org/10.1002/adfm.202103697

Hong YJ, Lee H, Kim J, et al (2018) Multifunctional Wearable System that Integrates Sweat-Based Sensing and Vital-Sign Monitoring to Estimate Pre-/Post-Exercise Glucose Levels. Adv Funct Mater 28:112. https://doi.org/10.1002/adfm.201805754

Jia L, Zeng S, Ding H, et al (2021) Leather-Based Multi-Stimuli Responsive Chromisms. Adv Funct Mater 2104427:1-8. https://doi.org/10.1002/adfm.202104427

Jiang Y, Cheng Y, Liu S, et al (2021) Solid-state intramolecular motions in continuous fibers driven by ambient humidity for fluorescent sensors. Natl Sci Rev 8.. https://doi.org/10.1093/nsr/nwaa135

Ju L, Gao W, Zhang J, et al (2020) A new absorption/fluorescence dual-mode hydrochromic dye for waterjet printing and anti-counterfeiting applications. J Mater Chem C 8:2806-2811. https://doi.org/10.1039/c9tc06522a

Jung SH, Lee HT, Park MJ, et al (2021) Precisely Tunable Humidity Color Indicator Based on Photonic Polymer Films. Macromolecules 54:621-628. https://doi.org/10.1021/acs.macromol.0c01911

Karimipour K, Keyvan Rad J, Ghomi AR, et al (2020) Hydrochromic and photoswitchable polyacrylic nanofibers containing spiropyran in eco-friendly ink-free rewriteable sheets with responsivity to humidity. Dye Pigment 175:108185. https://doi.org/10.1016/j.dyepig.2020.108185 
Kim SJ, Lee D, Chae JY, et al (2021) Reconfigurable, vivid reflective colors based on solution-processed Fabry-Perot absorber using thermochromic vanadium dioxide. Appl Surf Sci 565:150610. https://doi.org/10.1016/j.apsusc.2021.150610

Kim Y, Kim Y, Kim S, Kim E (2010) Electrochromic diffraction from nanopatterned poly(3-hexylthiophene). ACS Nano 4:5277-5284. https://doi.org/10.1021/nn1016378

Kitamura Y, Ichikawa R, Nakano H (2018) Reversible colour changes of mixed films composed of 4,40bis[bis(4-methylphenyl)amino]azobenzene and organic acids in response to exhaled breath. Mater Chem Front 2:90-95. https://doi.org/10.1039/c7qm00385d

Kou D, Ma W, Zhang S, et al (2018) High-Performance and Multifunctional Colorimetric Humidity Sensors Based on Mesoporous Photonic Crystals and Nanogels. ACS Appl Mater Interfaces 10:41645-41654. https://doi.org/10.1021/acsami.8b14223

Lan R, Gao Y, Shen C, et al (2021) Humidity-Responsive Liquid Crystalline Network Actuator Showing Synergistic Fluorescence Color Change Enabled by Aggregation Induced Emission Luminogen. Adv Funct Mater 31:1-7. https://doi.org/10.1002/adfm.202010578

Liu JJ, Sun ZL, Liu J, Xia SB (2021) A series of multi-responsive viologen-based alkaline-earth metal coordination complexes: Thermochromism, photochromism, and vapochromism. J Mol Struct 1238:130444. https://doi.org/10.1016/j.molstruc.2021.130444

Ma Y, Yu Y, Li J, et al (2021) Stimuli-responsive photofunctional materials for green and security printing. InfoMat 3:82-100. https://doi.org/10.1002/inf2.12125

Mao L, Wang Z, Duan Y, et al (2021) Designing of Rewritable Paper by Hydrochromic Donor-Acceptor Stenhouse Adducts. ACS Nano 15:10384-10392. https://doi.org/10.1021/acsnano.1c02629

Meng Y, Cao Y, Ji H, et al (2020) Fabrication of environmental humidity-responsive iridescent films with cellulose nanocrystal/polyols. Carbohydr Polym 240:116281.

https://doi.org/10.1016/j.carbpol.2020.116281

Mishra S, Singh AK (2021) Optical sensors for water and humidity and their further applications. Coord Chem Rev 445:214063. https://doi.org/10.1016/j.ccr.2021.214063

Momtaz M, Chen J (2020) High-Performance Colorimetric Humidity Sensors Based on Konjac Glucomannan. ACS Appl Mater Interfaces 12:54104-54116. https://doi.org/10.1021/acsami.0c16495

Nguyen T Van, Do HH, Trung TQ, et al (2021) Stable and multicolored electrochromic device based on polyaniline-tungsten oxide hybrid thin film. J Alloys Compd 882:160718.

https://doi.org/10.1016/j.jallcom.2021.160718 
$\mathrm{Ni}$ Y, Sun Z, Wang Y, et al (2019) Versatile hydrochromic fluorescent materials based on a 1,8naphthalimide integrated fluorophore-receptor system. J Mater Chem C 7:7399-7410. https://doi.org/10.1039/c9tc01304k

Park DH, Jeong W, Seo M, et al (2016a) Inkjet-Printable Amphiphilic Polydiacetylene Precursor for Hydrochromic Imaging on Paper. Adv Funct Mater 26:498-506.

https://doi.org/10.1002/adfm.201504088

Park DH, Park BJ, Kim JM (2016b) Hydrochromic Approaches to Mapping Human Sweat Pores. Acc Chem Res 49:1211-1222. https://doi.org/10.1021/acs.accounts.6b00128

Qi Y, Fan J, Chang Y, et al (2021) Smart photochromic fabric prepared via thiol-ene click chemistry for image information storage applications. Dye Pigment 193:109507.

https://doi.org/10.1016/j.dyepig.2021.109507

Samanta A, Chen H, Samanta P, et al (2021) Reversible dual-stimuli-responsive chromic transparent wood biocomposites for smart window applications. ACS Appl Mater Interfaces 13:3270-3277. https://doi.org/10.1021/acsami.0c21369

Sheng L, Li M, Zhu S, et al (2014) Hydrochromic molecular switches for water-jet rewritable paper. Nat Commun 5:. https://doi.org/10.1038/ncomms4044

Shi X, Deng Z, Zhang P, et al (2021) Wearable Optical Sensing of Strain and Humidity: A Patterned DualResponsive Semi-Interpenetrating Network of a Cholesteric Main-Chain Polymer and a Poly(ampholyte). Adv Funct Mater 2104641:2104641. https://doi.org/10.1002/adfm.202104641

Si P, Liang M, Sun M, Zhao B (2021) Nature-inspired robust hydrochromic film for dual anticounterfeiting. iScience 24:102652. https://doi.org/10.1016/j.isci.2021.102652

Stumpel JE, Broer DJ, Schenning APHJ (2015) Water-responsive dual-coloured photonic polymer coatings based on cholesteric liquid crystals. RSC Adv 5:94650-94653. https://doi.org/10.1039/c5ra18017a

Sun Z, Ni Y, Prakasam T, et al (2021) The Unusual Photochromic and Hydrochromic Switching Behavior of Cellulose-Embedded 1,8-Naphthalimide-Viologen Derivatives in the Solid-State. Chem - A Eur J. https://doi.org/10.1002/chem.202100601

Wen J, Sun Z, Xiang J, et al (2019) Preparation and characteristics of waterborne polyurethane with various lengths of fluorinated side chains. Appl Surf Sci 494:610-618.

https://doi.org/10.1016/j.apsusc.2019.07.170

Xu WJ, Chen KP, Zhang Y, et al (2021) Two new Co(II) coordination polymers based on redox-active ligands: Structure, Chromism and Magnetism. J Mol Struct 1231:129948.

https://doi.org/10.1016/j.molstruc.2021.129948

Page 14/ 25 
Yang T, Zuo Y, Feng S (2021) Rational design of photo-chromic molecule for constructing polysiloxanebased fluorescent films and anti-counterfeiting. Mater Des 207:109867.

https://doi.org/10.1016/j.matdes.2021.109867

Yang XD, Zhu R, Yin JP, et al (2018) Bipyridinium-Bearing Multi-stimuli Responsive Chromic Material with High Stability. Cryst Growth Des 18:3236-3243. https://doi.org/10.1021/acs.cgd.8b00390

Yao Y, Yin C, Hong S, et al (2020) Lanthanide-ion-coordinated supramolecular hydrogel inks for 3D printed full-color luminescence and opacity-tuning soft actuators. Chem Mater 32:8868-8876.

https://doi.org/10.1021/acs.chemmater.0c02448

Yoo GY, Lee S, Ko M, et al (2020) Diphylleia grayi-Inspired Intelligent Hydrochromic Adhesive Film. ACS Appl Mater Interfaces 12:49982-49991. https://doi.org/10.1021/acsami.0c13185

You MH, Yan X, Zhang J, et al (2017) Colorimetric Humidity Sensors Based on Electrospun Polyamide/CoCl2 Nanofibrous Membranes. Nanoscale Res Lett 12:. https://doi.org/10.1186/s11671-0172139-0

Yu X, Wu L, Yang D, et al (2020) Hydrochromic CsPbBr3 Nanocrystals for Anti-Counterfeiting. Angew Chemie - Int Ed 59:14527-14532. https://doi.org/10.1002/anie.202005120

Zhang F, Liu W, Wang S, et al (2019) A novel and feasible approach for polymer amine modified graphene oxide to improve water resistance, thermal, and mechanical ability of waterborne polyurethane. Appl Surf Sci 491:301-312. https://doi.org/10.1016/j.apsusc.2019.06.148

Zhang W, Ji X, Peng BJ, et al (2020) High-Performance Thermoresponsive Dual-Output Dye System for Smart Textile Application. Adv Funct Mater 30:1-8. https://doi.org/10.1002/adfm.201906463

Zhou L, Wang M, Liu Z, et al (2021) High-performance humidity sensor based on graphitic carbon nitride/polyethylene oxide and construction of sensor array for non-contact humidity detection. Sensors Actuators, B Chem 344:130219. https://doi.org/10.1016/j.snb.2021.130219

\section{Scheme 1}

Scheme 1 is available in the Supplementary Files section.

\section{Figures}




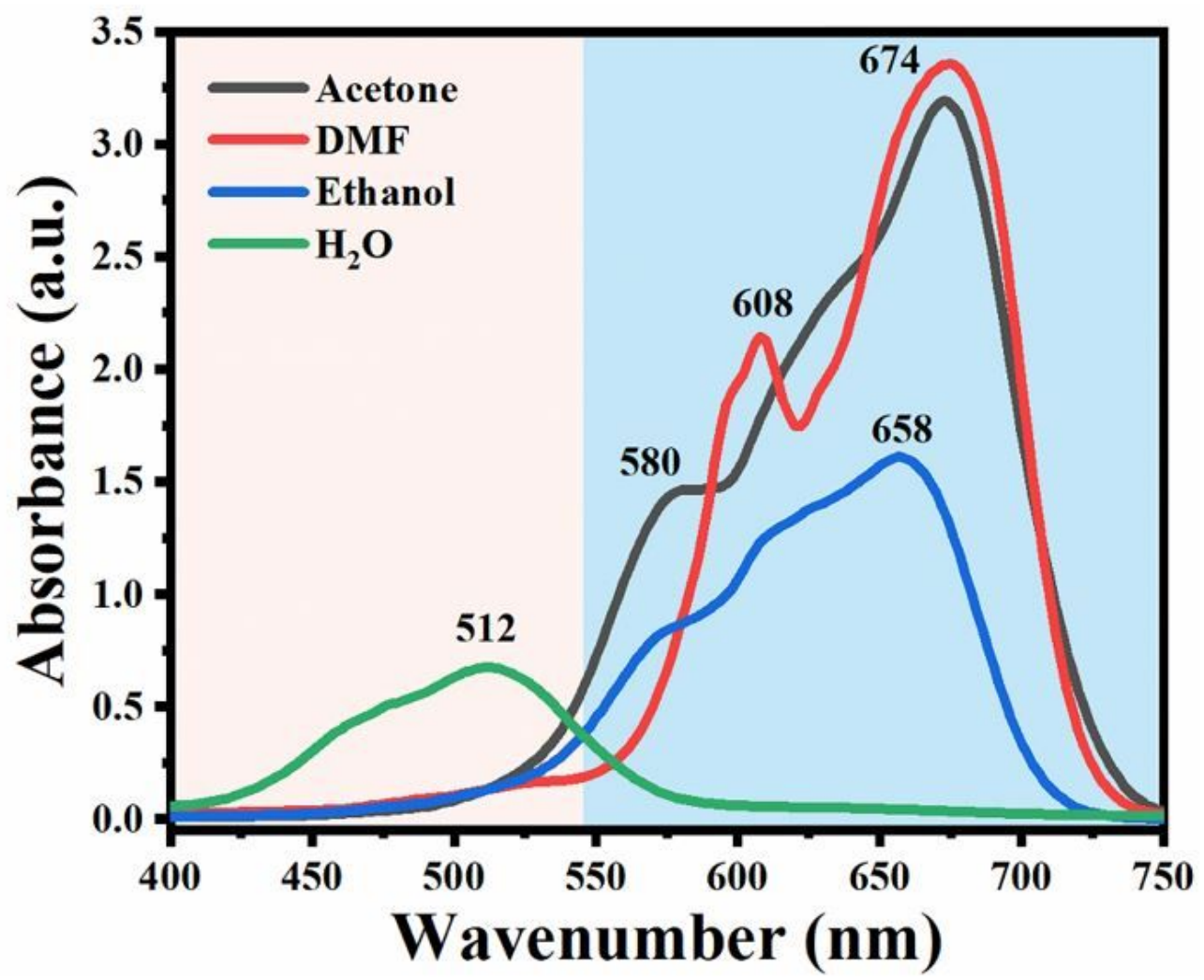

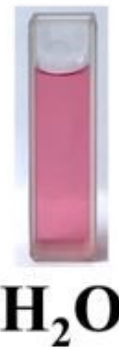

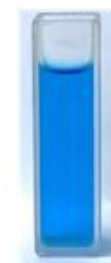

DMF

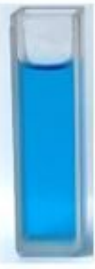

Acetone

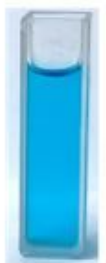

Ethanol

Figure 1

UV-vis spectra of $\mathrm{CoCl} 2 \cdot 6 \mathrm{H} 2 \mathrm{O}$ in $\mathrm{H} 2 \mathrm{O}, \mathrm{DMF}$, acetone and ethanol 


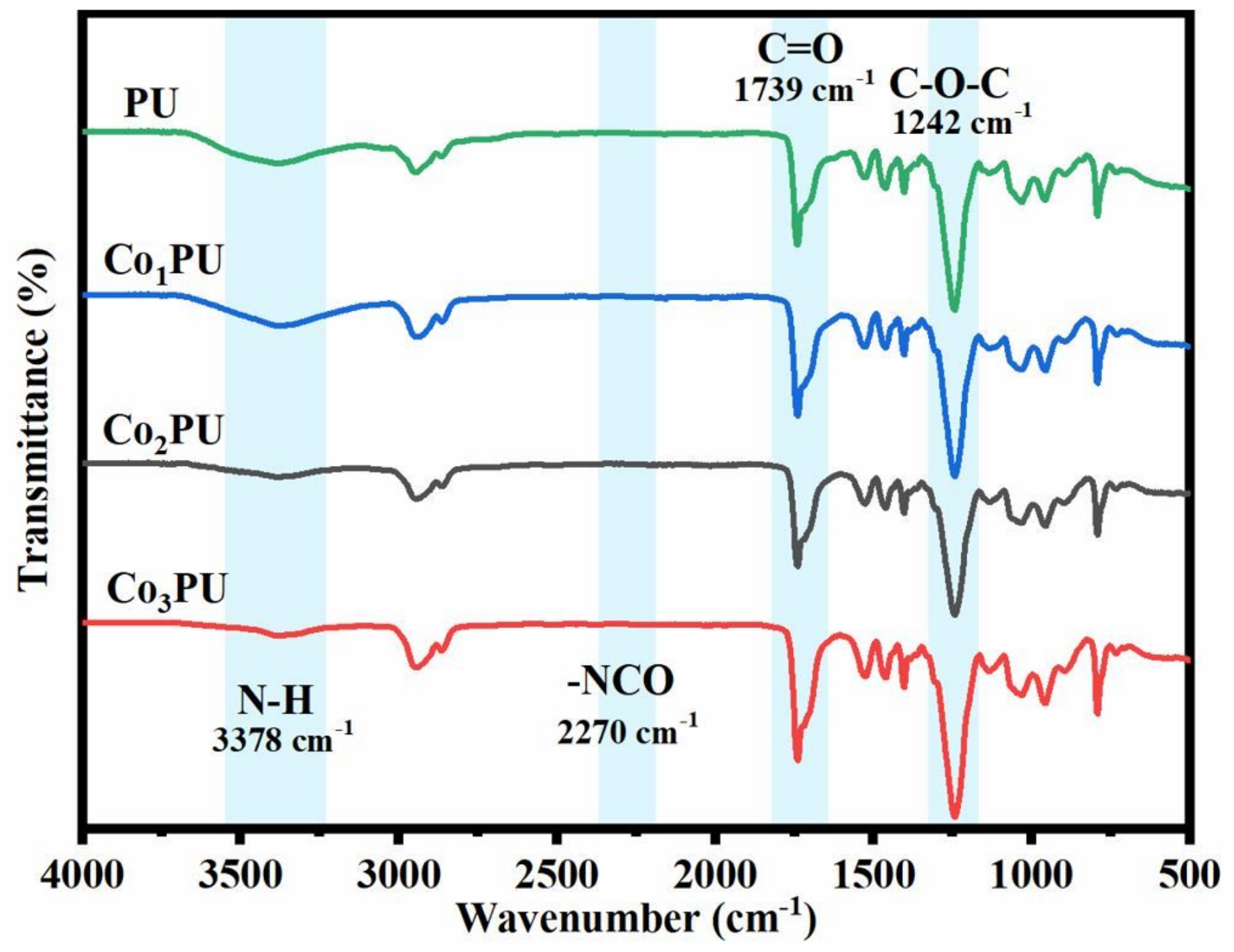

Figure 2

FTIR spectra of $\mathrm{CoCl} 2 \cdot 6 \mathrm{H} 20$ /waterborne polyurethane (CoPU) films 


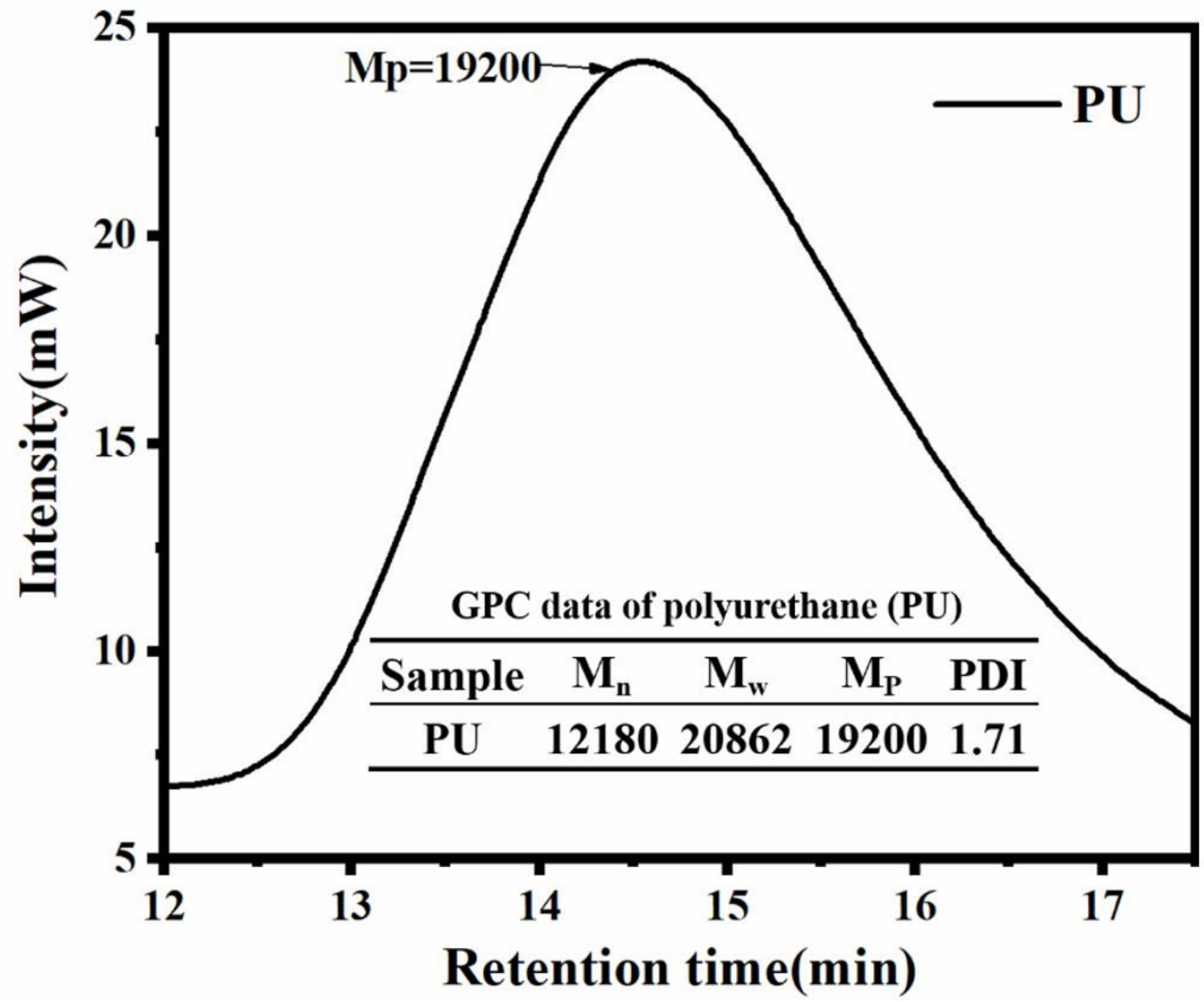

Figure 3

GPC spectra of polyurethane (PU). 
(a)

(d)
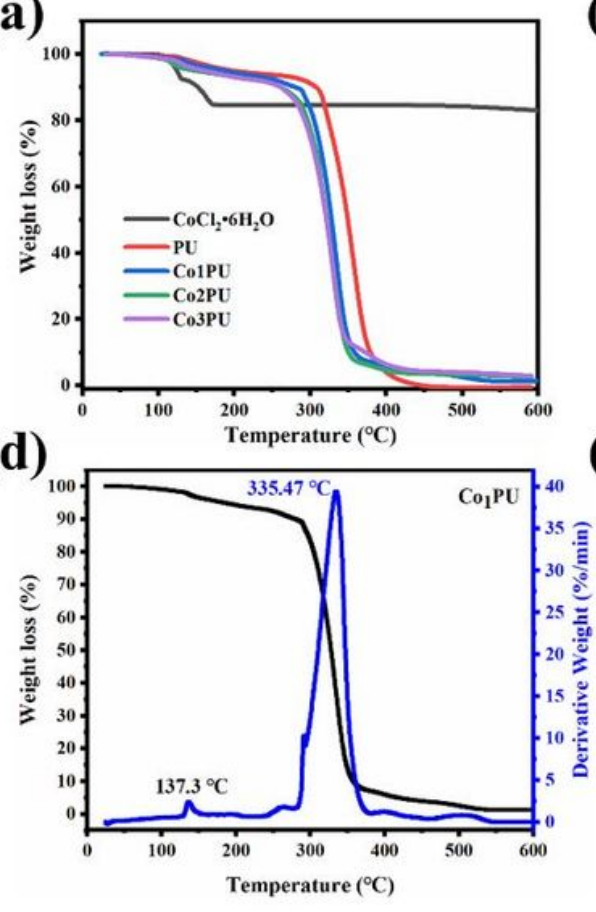

(b)

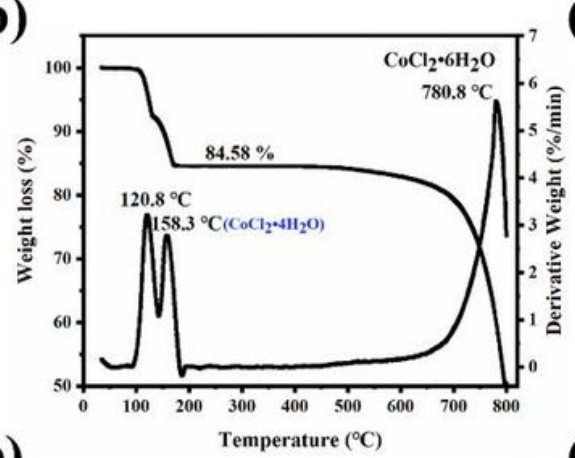

(e)

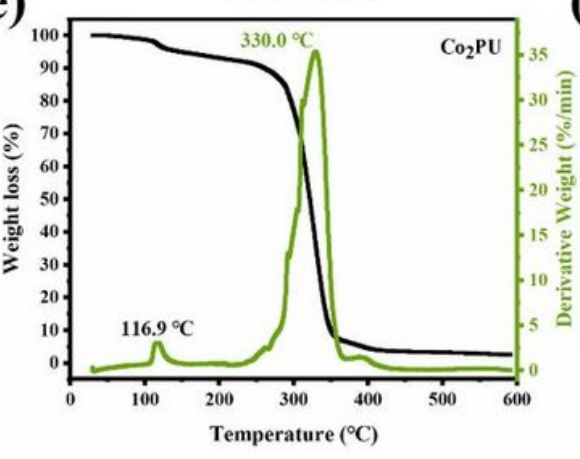

(c)

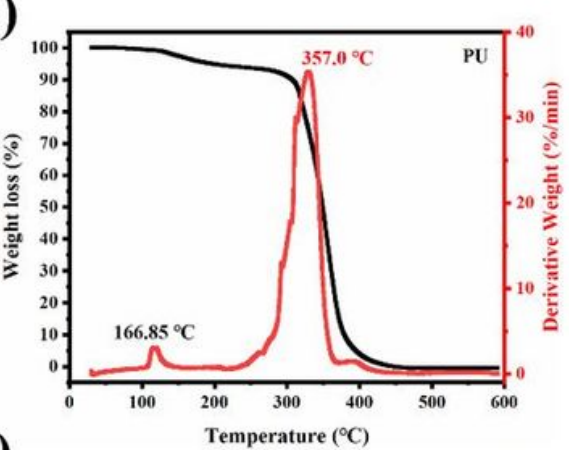

(f)

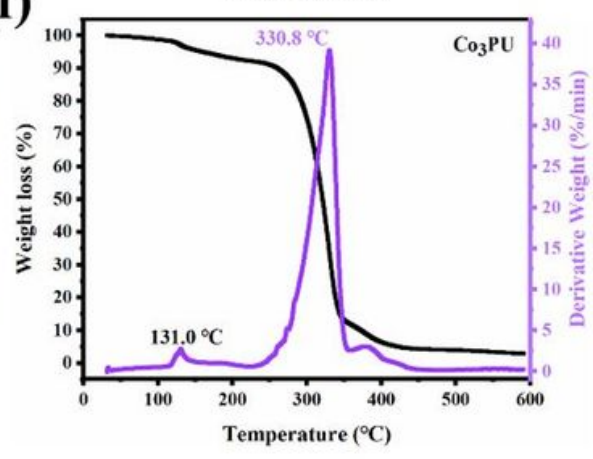

Figure 4

TG and DTG of (a) TG spectrum of $\mathrm{CoCl} 2 \cdot 6 \mathrm{H} 2 \mathrm{O}$ and four polyurethanes; (b) $\mathrm{CoCl} 2 \cdot 6 \mathrm{H} 2 \mathrm{O}$;(c) PU; (d)Co1PU; (e)Co2PU; (f)Co3PU
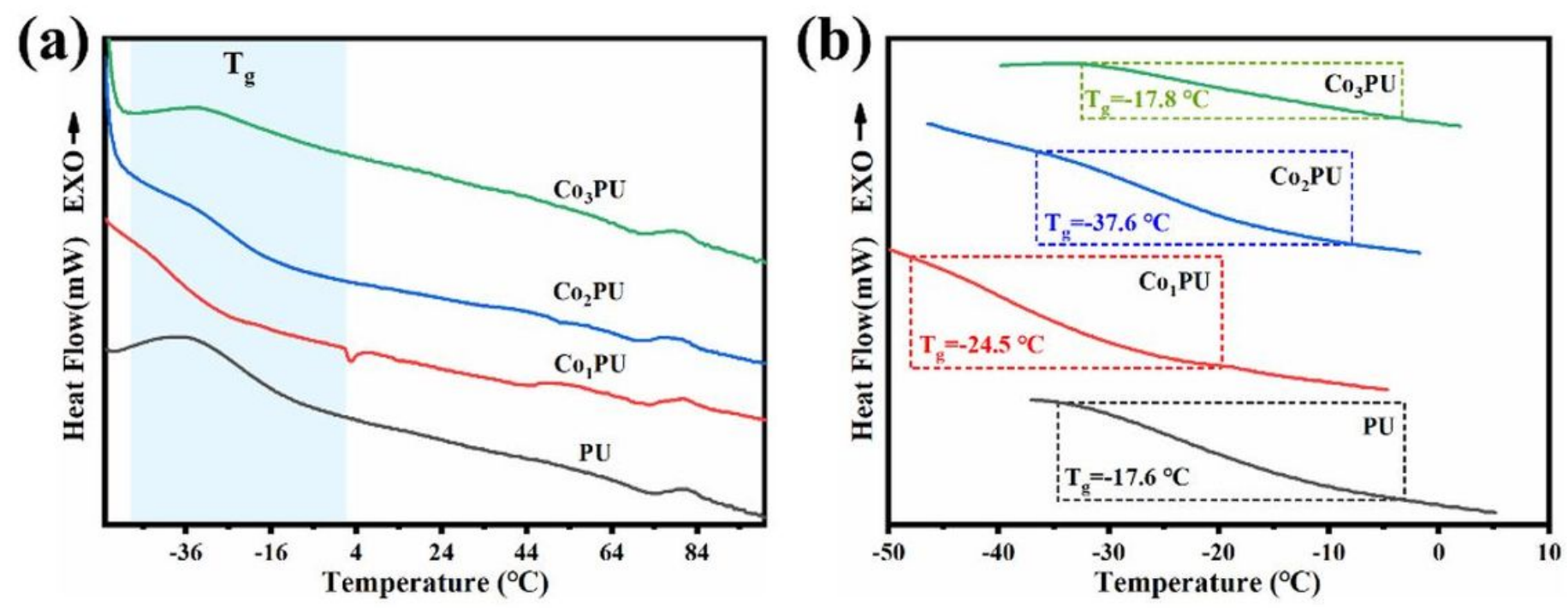

Figure 5

DSC curves of $\mathrm{CoCl} 2 \cdot 6 \mathrm{H} 2 \mathrm{O} /$ waterborne polyurethane (CoPU) films. 

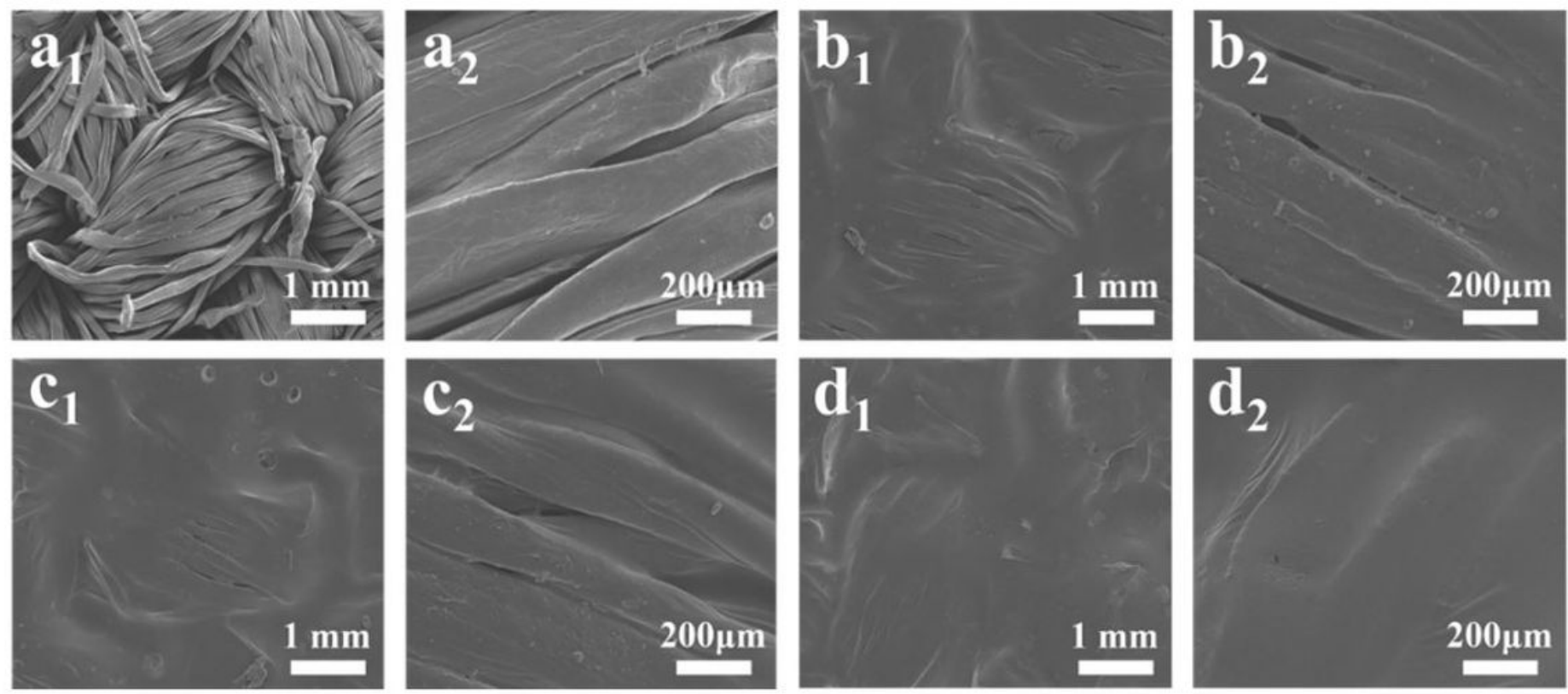

Figure 6

SEM images of (a1-a2) cotton fabric; (b1-b2) Co1PU hydrochromic cotton fabric; (c1-c2) Co2PU hydrochromic cotton fabric; (d1-d2) Co3PU hydrochromic cotton fabric.
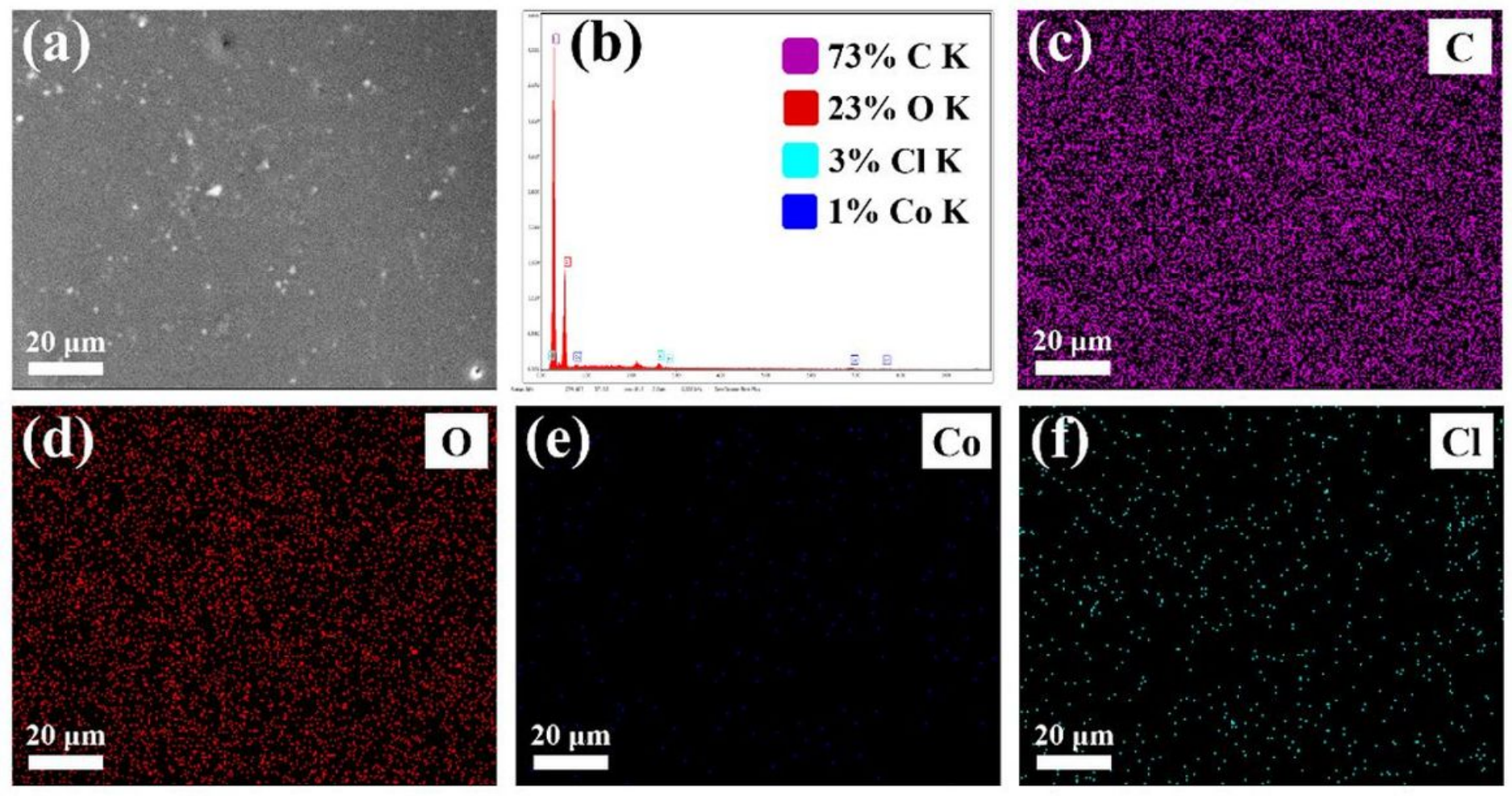

Figure 7

EDS of Co3PU hydrochromic cotton fabric 


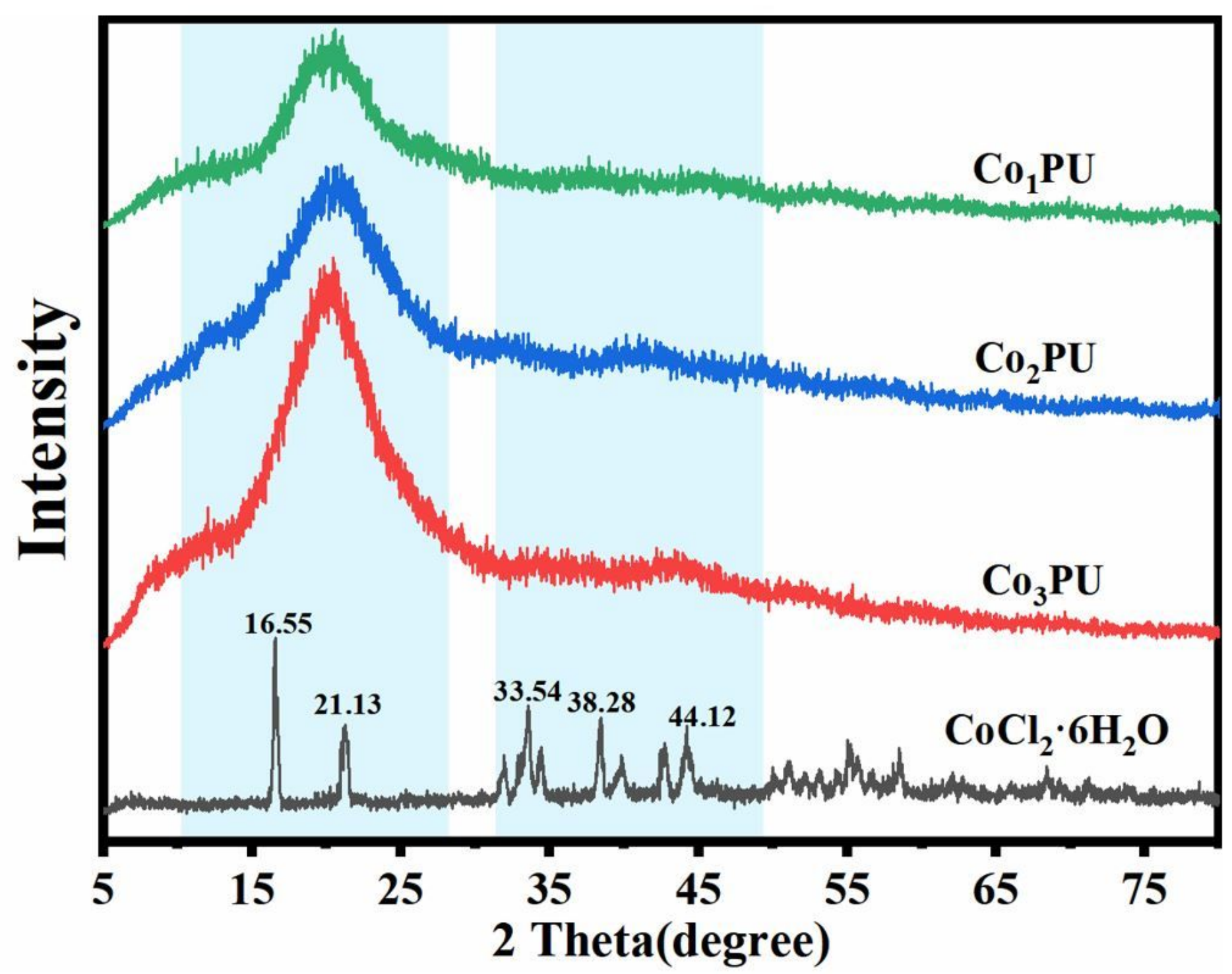

Figure 8

XRD of CoPU hydrochromic cotton fabric 


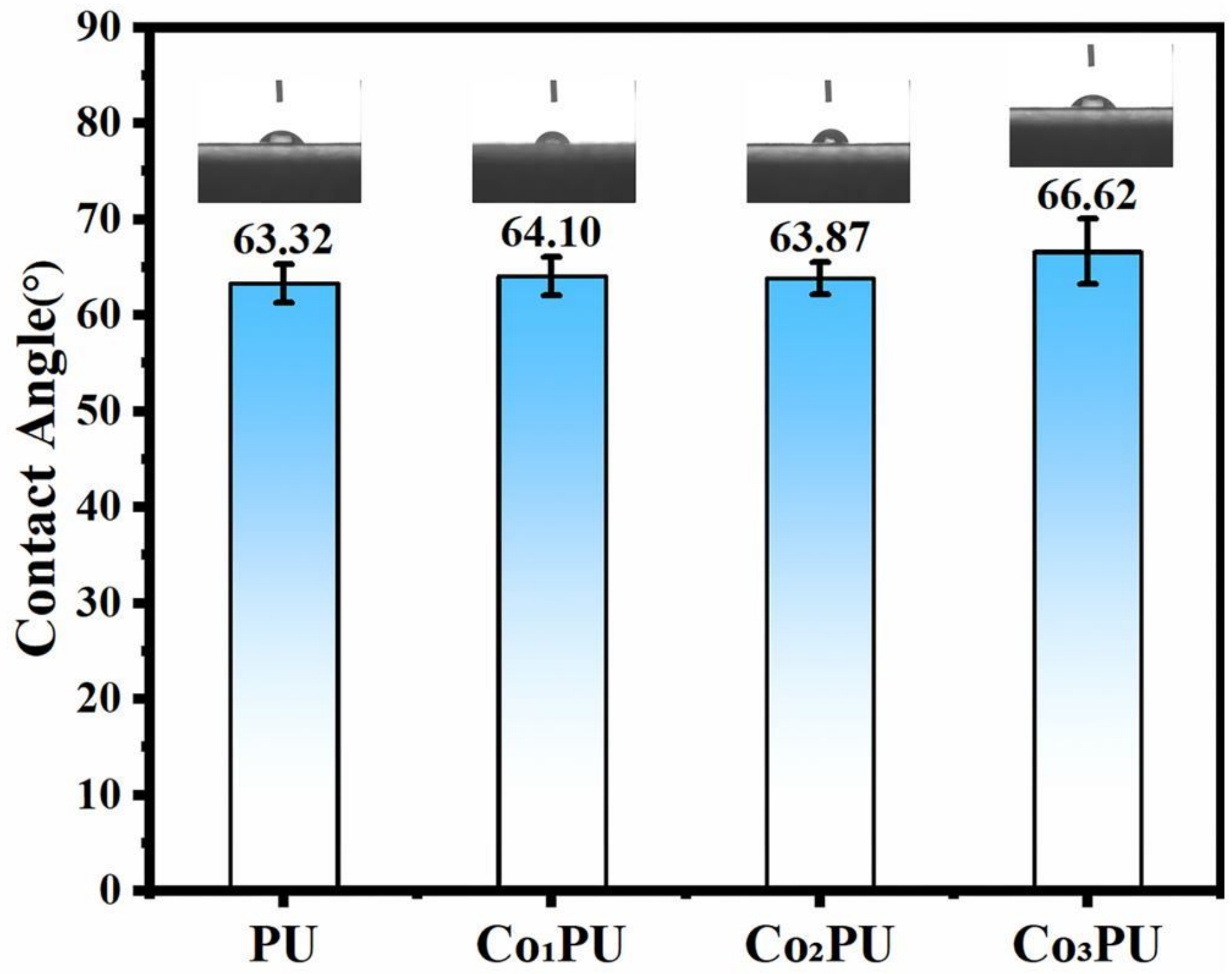

Figure 9

Analysis of contact angle of CoPU hydrochromic cotton fabric 
(a)
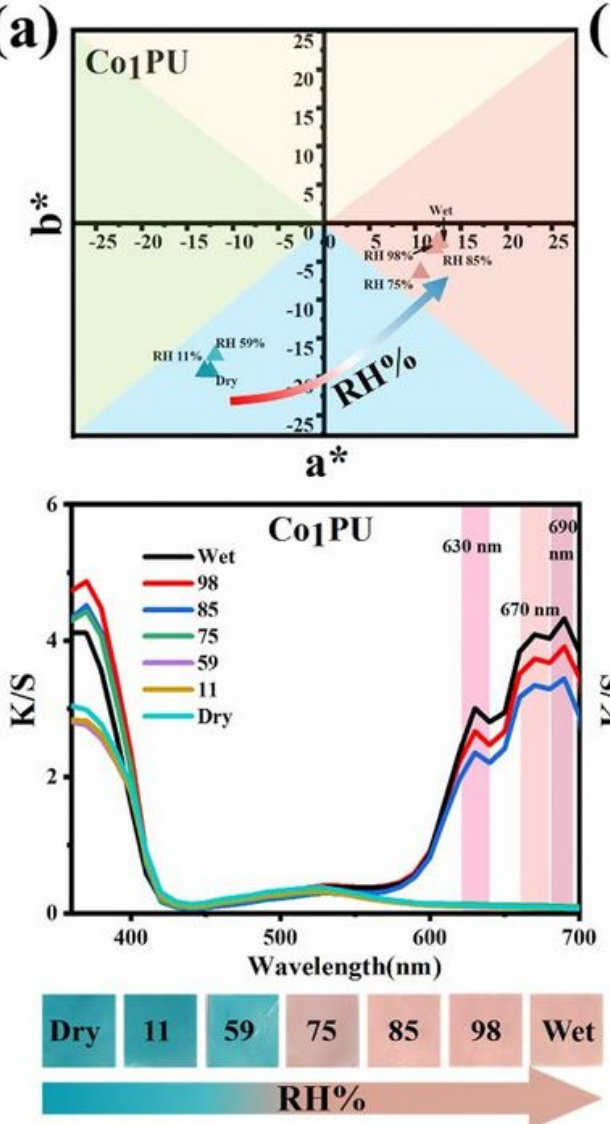

(b)
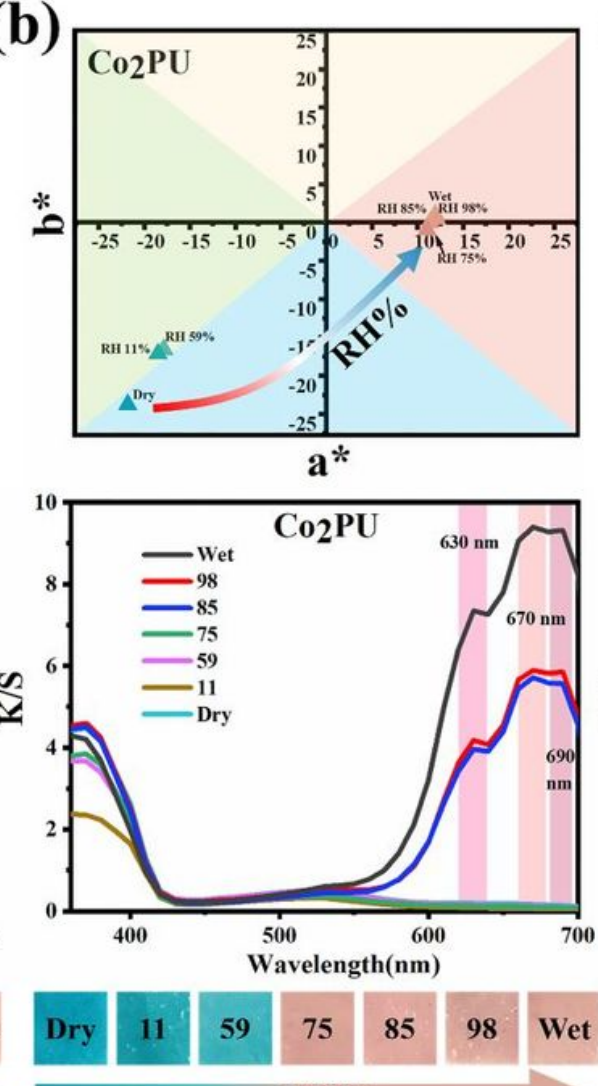

RH\%
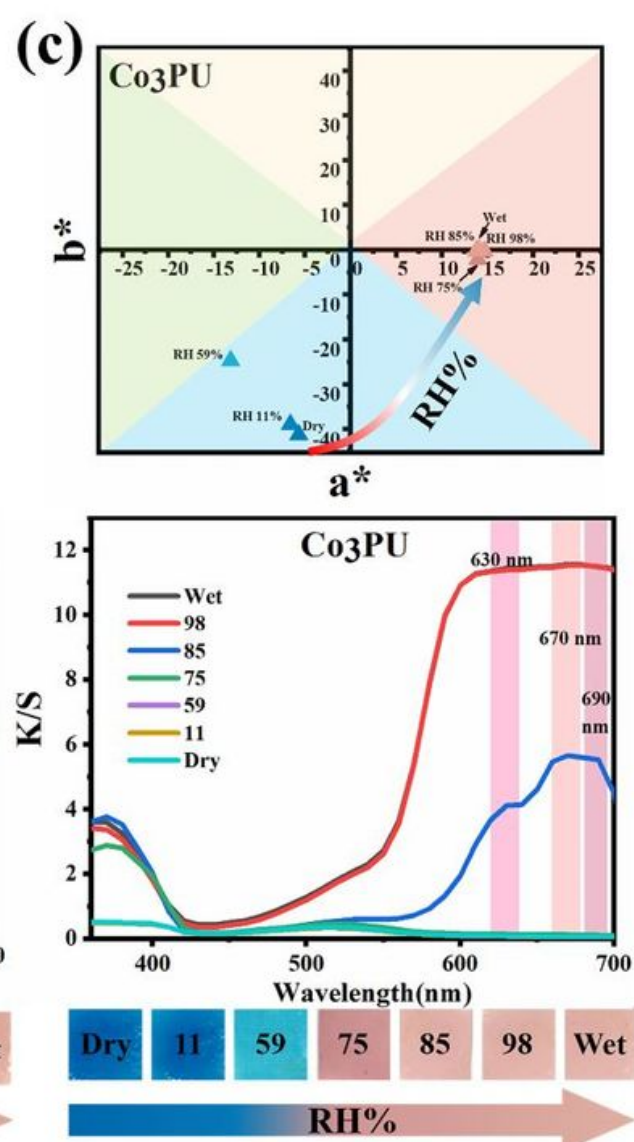

Figure 10

Hydrochromic performance of CoPU hydrochromic cotton fabric(a) Co1PU hydrochromic cotton fabric; (b) Co2PU hydrochromic cotton fabric; (c) Co3PU hydrochromic cotton fabric. 


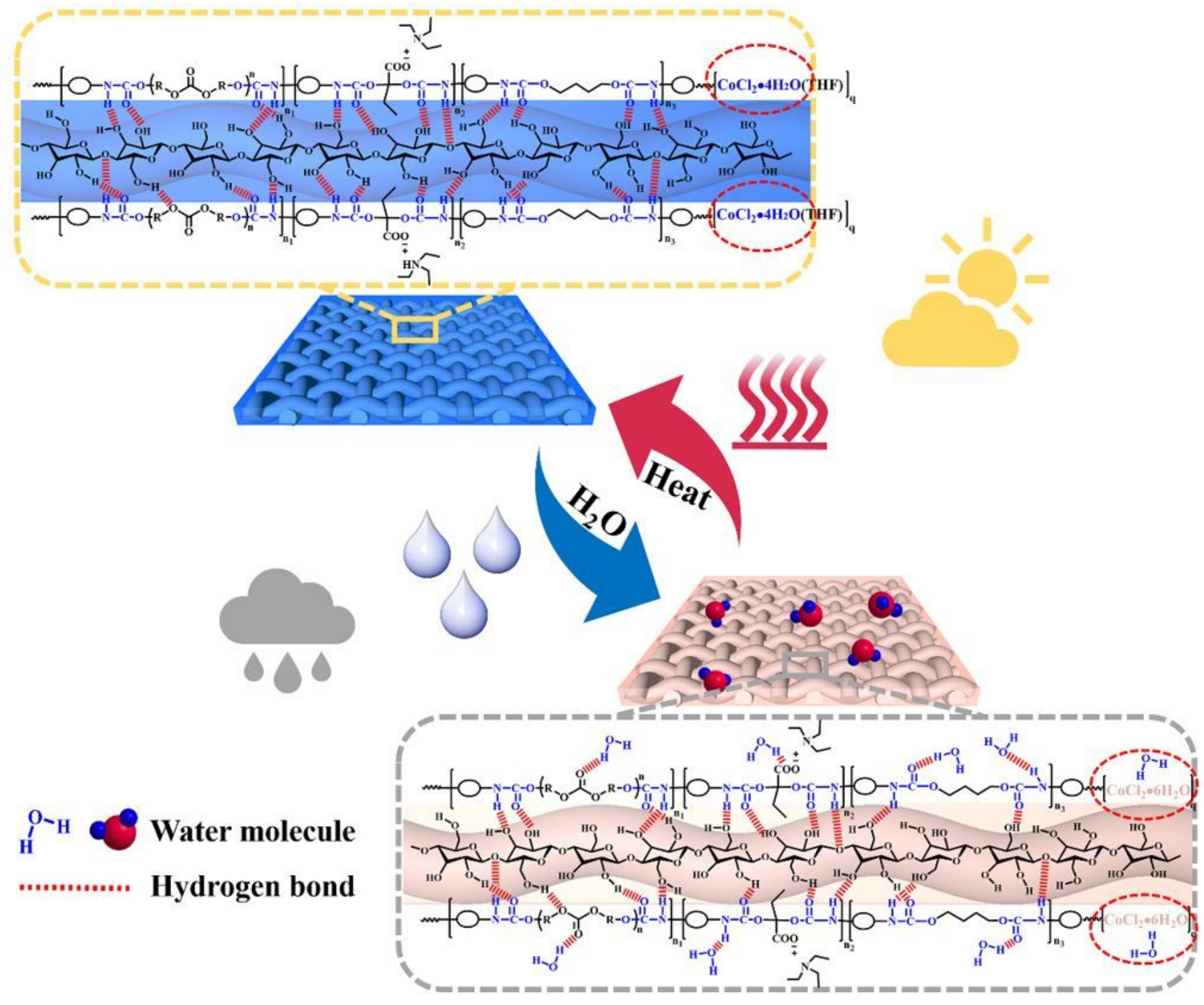

Figure 11

Schematic diagram of the cyclic discoloration process of CoPU hydrochromic cotton fabric 

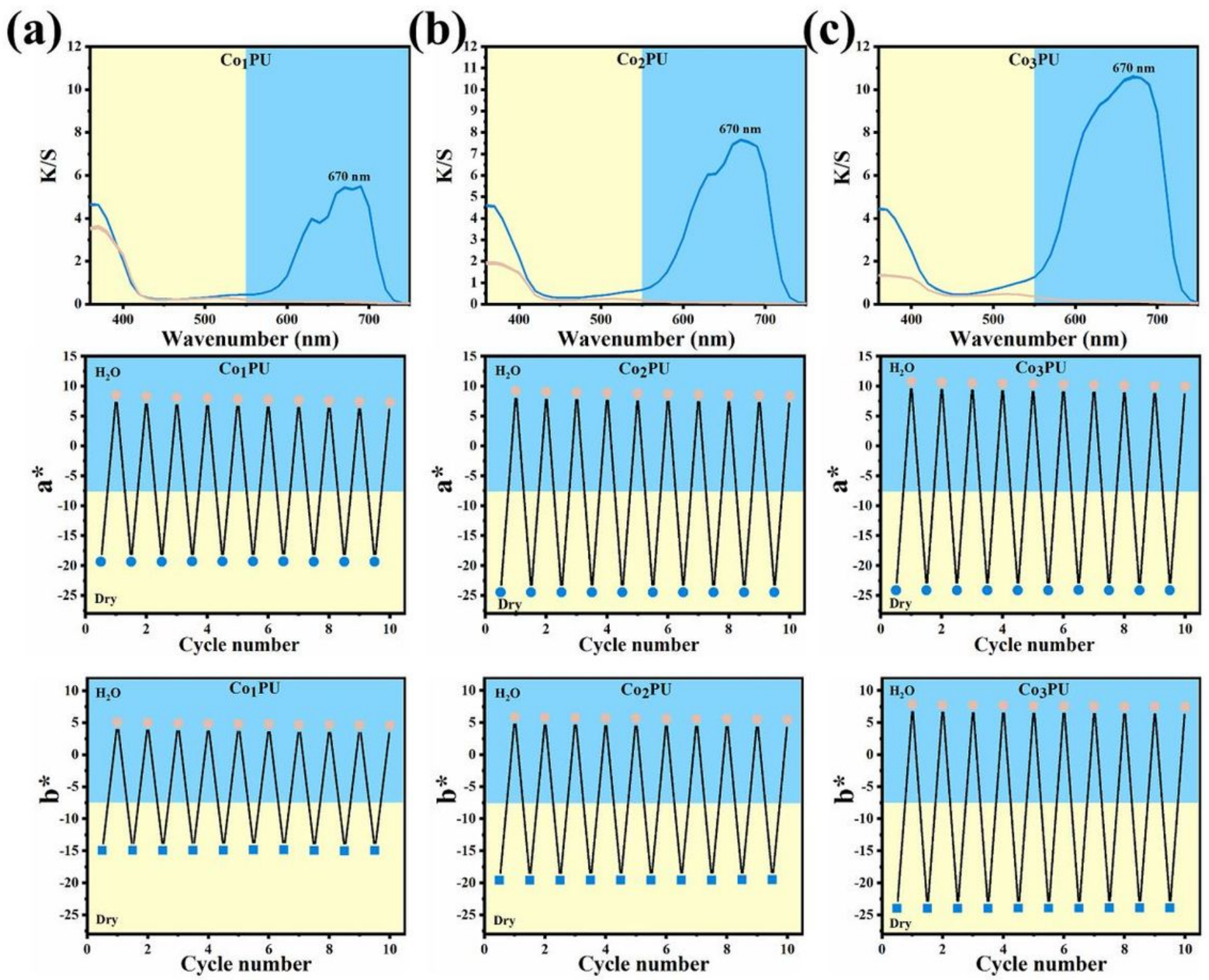

Figure 12

Hydrochromic cycle performance of CoPU hydrochromic cotton fabric (a) Co1PU hydrochromic cotton fabric; (b) Co2PU hydrochromic cotton fabric; (c) Co3PU hydrochromic cotton fabric.

\section{Supplementary Files}

This is a list of supplementary files associated with this preprint. Click to download.

- scheme1.jpg 